\title{
ANNIE ERNAUX: UNA AUTOBIOGRAFÍA SOMETIDA A CONSTANTE AUTORREVISIÓN
}

\author{
ANNIE ERNAUX: AN AUTOBIOGRAPHY SUBMITTED \\ TO CONSTANT SELF-REVIEW
}

\author{
Francisca ROMERAL ROSEL \\ Universidad de Cádiz \\ francisca.romeral@uca.es
}

\begin{abstract}
Resumen: Anotar, exhibir, revisar, dilatar, cuestionar lo más íntimo de su propia vida, son prácticas recurrentes en Annie Ernaux. Revelan un sentimiento de rebeldía frente a lo infinito del tiempo. Su obra tiende hacia la "autobiographie impersonnelle" (Ernaux, 2008: 240) -bajo la influencia, como la escritora misma reconoce, de las lecturas de Bourdieu-, una autobiografía en la que el yo es transpersonal y remite a la historia colectiva. Con Les Années, su trayectoria vital y su proyecto de escritura se imbrican definitivamente. La vergüenza, tema fundador, y la imagen fotográfica, son caudales inagotables de recuerdos.
\end{abstract}

Palabras clave: Autobiografía. Vergüenza. Sociedad. Annie Ernaux.

Abstract: To annotate, to exhibit, to review, to expand, to make clear the most intimate parts of her own life, are recurring practices in Annie Ernaux. They reveal a feeling of rebellion against the infinity of time. Her work tends towards an "autobiographie impersonnelle" (Ernaux, 2008:240) under the influence, as the writer herself acknowledges, of Bourdieu's 
works-, a kind of autobiography in which the self is transpersonal and refers to the collective history. With Les Années, her life's trajectory and her writing project definitely interweave. Shame, the founding theme, and photographic image are inexhaustible flows of memories.

Key Words: Autobiography. Shame. Society. Annie Ernaux.

Ce que je désire est impossible, c'est revivre les choses (Ernaux, 2011c: 54).

En septiembre de 1960, tras haber abandonado en el mes de febrero de ese mismo año la Escuela Normal de Institutrices de Rouen por falta de vocación, y haber pasado después unos meses en Londres con su amiga R. como chicas au pair, Annie Ernaux inicia sus estudios en la Facultad de Filosofía de Rouen. Tiene diecinueve años y ha confeccionado una "liste performative" (Ernaux, 2016: 97) para ser una excelente estudiante y superar en todos los aspectos a la joven atolondrada e inexperta que fue durante el verano de $1958^{1}$. Lejos del ambiente provinciano de Yvetot, lejos de sus padres, modestos comerciantes que siguen ocupándose de su bar-tienda de comestibles, la joven becaria se siente por fin totalmente libre. Al igual que en el verano de 1958, cuando por primera vez en su vida se separó de sus padres, se siente "dans la légèreté d'être déliée des yeux de sa mère" (Ernaux, 2016: 59), liberada de la vigilancia celosa de una madre posesiva y exigente, que llegó a sustraerle su agenda y su diario íntimo de 1958 para quemarlos después en 1960. Por fin va a poder escribir sin esconderse. A través de la lectura de autores hasta entonces desconocidos para ella, de libros de filosofía, de la frecuentación de sus compañeros de estudio y de nuevos encuentros, su vida va a dar un vuelco. Es por aquella época cuando, sin confesárselo aún - aunque ya estaba entrenada en el ejercicio de la escritura -, empieza a fraguarse su vocación de escritora y

1. Durante los meses de verano de 1958, Annie Duchesne (Annie Ernaux, antes de contraer matrimonio con Philippe Ernaux) es monitora en una colonia de verano. Es la primera vez que se aleja de sus padres y la primera también que tiene una relación física con un hombre, H., el monitor principal, y luego con otros chicos del campamento. H. la desprecia al día siguiente de ese primer encuentro, convirtiendo a la joven en el hazmerreír de la colonia. Annie Ernaux relata este episodio sobresaliente, generador de vergüenza, en Mémoire de fille (2016). 
deviene poco a poco un "être littéraire, quelqu'un qui vit les choses comme si elles devaient être écrites un jour” (Ernaux, 2016: 143).

\section{ANNIE ERNAUX: FIGURA DE REFERENCIA DENTRO DEL PANORAMA LITERARIO DE LA ESCRITURA AUTOBIO- GRÁFICA EN FRANCIA}

Annie Ernaux tiene el mérito de haber sabido renovar la autobiografía transcendiendo lo íntimo, imprimiendo al género una relevancia sociológica. Más allá del retrato suyo universalmente difundido como autora de $L a$ Place, un auténtico best seller, Annie Ernaux es parte hoy en día de la cultura popular francesa y sigue reflejando, en la estela de Simone de Beauvoir, el empoderamiento de toda una generación de mujeres nacidas alrededor de los años 40. Observando el mundo al sesgo de su propia vida -las diferencias de clase, el acceso a la educación y a los bienes culturales, la enfermedad de Alzheimer ${ }^{2}$, el aborto ${ }^{3}$, la pasión amorosa ${ }^{4}$, la vergüenza de los orígenes humildes, la condición de ser mujer...- ha conseguido que sus experiencias concernieran a muchos, que fueran un espejo en el que se reflejaran vidas ajenas. Posee para sus lectores ese don hipnótico de evocación al que alude Gaston Bachelard en Poétique de l'espace:

Les valeurs d'intimité sont si absorbantes que le lecteur ne lit plus votre chambre: il revoit la sienne. Il est déjà parti écouter les souvenirs d'un père, d'une aïeule, d'une mère, d'une servante, de la "servante au grand cœur", bref, de l'être dominant le coin de ses souvenirs les plus valorisés (Bachelard, 1961 [1957]: 42).

Su estilo casi fotográfico, preciso, depurado, ha conseguido el apego de los lectores a su narrativa. Irrumpió en el ámbito literario en un momento propicio, mediados de los 70 y principios de los 80 , años

2. Annie Ernaux abordó este tema en "Je ne suis pas sortie de ma nuit" (1997b), el diario íntimo donde da cuenta de las visitas que hizo a su madre, ya mayor, enferma de Alzheimer y recluida en un sanatorio.

3. Annie Ernaux cuenta en Les armoires vides (1974) y, años más tarde, en L'événement (2000), su aborto en 1964, cuando esta práctica era aún delictiva. Sería legalizada en 1974 a propuesta de la entonces ministra de Salud, Simone Veil, nueve meses después de la publicación de Les armoires vides.

4. Sobre el tema de la pasión amorosa, Annie Ernaux ha publicado cuatro textos autobiográficos: Passion simple (1991), Se perdre (2001b), L'Occupation (2002), L'usage de la photo (2005b).

5. Votre: perteneciente al escritor. 
en los que las editoriales francesas se volvieron sensibles a los cambios de mentalidad. Al igual que Claude Gallimard -el editor de Annie Ernaux, que había tomado recientemente el relevo de su padre, Gaston Gallimard, y que cedería en 1988 la dirección de la editorial a su hijo Antoine- estas editoriales apostaron por una clase de jóvenes aspirantes a la literatura, escritores noveles que conectaban de forma muy directa con lectores nacidos, como ellos, en el periodo de la segunda guerra mundial, y con los que compartían una historia común, nuevas preocupaciones, una misma visión acerca de las transformaciones que convulsionaron su entorno y su país. Desde un principio, la intrusión mediática ${ }^{6}$ en el campo literario creó sin duda una telemitología en torno a la figura de estos escritores recién incorporados al mundo editorial y en particular de Annie Ernaux, presentándola como un ser coherente, concreto, accesible, inseparable de su obra, propiciando de este modo la buena recepción de su obra. Las condiciones de la literatura contemporánea que exigían al escritor mostrarse en actos públicos, participar en coloquios y debates universitarios y televisivos, y conceder entrevistas publicadas luego en periódicos - no sólo en Le Monde, por ejemplo, sino también en pequeños diarios de provincias- y revistas -no sólo en Le Nouvel Observateur o La Quinzaine littéraire, por citar dos de entre muchas, sino también en revistas de moda como Elle o Femme d'aujourd'hui-, favorecieron a Annie Ernaux porque consolidaron -y siguen afianzando hoy en día- la fidelización de un lectorado de clase media con un pasado parecido al suyo. Su nombre saltó a la fama el viernes 6 de abril de 1984, al acudir la escritora como invitada al programa literario Apostrophes $^{8}$, dirigido por Bernard Pivot y emitido por la cadena de televisión francesa A2, para presentar su cuarto libro, La Place, publicado el año anterior. Apostrophes era "l'instance de consécration [...], [1']épreuve initiatique qui [1'] adouberait écrivain" (Ernaux, 2001a: 22]. La participación de Ernaux en el programa iba a originar de inmediato un aumento considerable de

6. Ver a este propósito el libro de Jean-Philippe Domecq, Qui a peur de la littérature? (2002) y su artículo "La passion pour l'écriture engendre la célébration janséniste de l'écritûûûre" (2007).

7. Término utilizado por el sociólogo norteamericano Michael Schudson en su ensayo The Power of News (1995), en el que analiza la participación de la prensa y de la televisión en la creación de mitos, especialmente a través del género de la entrevista.

8. Apostrophes se llamará años después Bouillon de culture. Bernard Pivot seleccionaba tan rigurosamente a los escritores que Pierre Bergounioux, por ejemplo, fue invitado al programa después de haber escrito una treintena de libros. 
recepción a la vez que la reedición de sus libros anteriores ${ }^{9}$ a La Place en la colección Folio. El 12 de noviembre de ese mismo año, La Place sería galardonado con el Prix Théophraste-Renaudot. Pocos días después, el 17 de noviembre, Ernaux escribiría en su diario íntimo que La Place, el Renaudot, era "le livre qui rachète tout" (Ernaux, 2011a: 84), el libro que le había permitido, de alguna manera, llenar los armarios vacíos ${ }^{10}$ de su infancia, dignificar no sólo la figura de su padre, un ciudadano francés como otros muchos, sino también dar voz a varias generaciones de franceses que la Historia había dejado de lado. La Place era un himno con el que Ernaux se había propuesto ya entonces "venger sa race" (Ernaux, 2011b), hacerle un sitio en la memoria colectiva, salvar el recuerdo de la gente común, de lo popular, de sus costumbres y de su modo de hablar, el de su propia familia, cuya vida anodina no tenía cabida en la gran literatura académica: "Je ferais, au delà de l'histoire de mon père, un désir de justice et de réparation des humiliations sociales et culturelles" (Ernaux, 2001a: 22). Sin embargo, esta empresa no la salvará de seguir sintiéndose una "transfuge de classe" 11 porque ser reconocida como escritora es "appartenir réellement (dans la manière de vivre, la possibilité de voyager, etc.) au monde dominant, très dominant même" (Laacher, 1991: 77).

Con el paso del tiempo, desde La Place, ha quedado evidenciado que dentro del panorama de la literatura autobiográfica en lengua francesa, Annie Ernaux, que obtuvo en 2008 el Prix de la Langue Française en reconocimiento al conjunto de su obra, es una referencia ineludible. $L a$ Place y Passion simple han sido traducidos a más de veinticinco idiomas. En el mes de marzo de 2006, salía en librería la quinta edición de La Place en la colección Folio Plus - Classiques du XXe siècle. Este hecho inusitado tratándose de una escritora aún en vida confirmaba que Annie Ernaux había sido elevada a la categoría de autor clásico, de alguna manera inmortal. La relativa intemporalidad a la que alude el término clásico es inherente a los títulos de tres de sus últimos libros: Les Années ${ }^{12}$ (2008), Écrire la

9. Les armoires vides (1974); Ce qu'ils disent ou rien (1977); La femme gelée (1981).

10. Annie Ernaux tiene treinta y tres años cuando publica Les armoires vides en 1974. La venta de seis mil ocho cientos ejemplares, ese mismo año, la hacen merecedora de reconocimiento público.

11. Esta expresión, acuñada por Richard Hoggart en La Culture du pauvre (1970), designa en sociología a las personas que están en posesión de un título académico superior al que se esperaba que obtuvieran en consideración de su clase social de origen. Así, Annie Ernaux ascendió socialmente, se trasladó de clase social, al licenciarse en la Facultad de Filosofía y obtener un puesto de profesora de literatura en un centro de Enseñanza Media cuando estaba destinada a ser, a lo sumo, institutriz.

12. Obra galardonada con el Prix Marguerite-Duras y el Prix François-Mauriac. 
$v_{i} e^{13}$ (2011) y Mémoire de fille (2016), que evocan el paso de los años por espacios íntimos, el fluir de la vida por lugares muy concretos, en particular los de la infancia y de la adolescencia, el resarcimiento de la memoria, libros que desgarran el "tissu temporel conjonctif sans action sur notre destin" (Bachelard, 1961 [1957]: 37) y ponen a la vista que "plus urgente que la détermination des dates est, pour la connaissance de l'intimité, la localisation dans les espaces de notre intimité" (Bachelard, 1957 [1961]: 37). Para Ernaux, "écrire c'est retenir la vie" (Ernaux, 2011c: 62), es un intento de perpetuar lo vivido, de desacralizar la muerte, el miedo a desaparecer sin dejar rastro, como el que la atenaza cuando se entrega a alguna "promenade de reviviscence" (Ernaux, 2011c: 52) con la esperanza de poder revivir lo vivido antaño en distintos lugares: "Dans un voyage de retour, initiatique, tout se résume à 'ouvert', 'fermé', encore là/plus là. Renvoyant à notre propre disparition" (Ernaux, 2011c: 52). Abundan escritores cuyo pensamiento se refleja en el de Ernaux; entre ellos, por ejemplo, Kamel Daoud, escritor y periodista argelino, en el transcurso de una entrevista en France Culture: "Écrire est une résistance, une façon de ne pas mourir" (Hakem, 2017). En esta necesidad de luchar contra la vorágine del tiempo se fundamentan los principios de su escritura autobiográfica acerada $^{14}$, que a partir de La Place "est vraiment sous-tendue par la conscience de rapports entre [sa] situation de narratrice à l'intérieur du livre, et [sa] situation dans le monde social" (Laacher, 1991: 77). Estas dos perspectivas-el yo escribiente que se narra y el yo sumergido en su entorno ${ }^{15}$ se pueden diferenciar, pero son inseparables, participan la una de la otra:

Je n'ai pas cherché à m'écrire, à faire ouvre de ma vie: je me suis servie d'elle, des événements, généralement ordinaires qui l'ont traversée, des situations et des sentiments qu'il m'a été donné de connaître, comme d'une matière à explorer pour saisir et mettre au jour quelque chose de l'ordre d'une

13. Écrire la vie reúne once obras de Ernaux, extractos de su diario íntimo, fotos y textos diversos.

14. A este tipo de escritura hace directamente alusión el título de la larga entrevista escrita a cuatro manos por Annie Ernaux y Frédéric-Yves Jeannet, L'écriture comme un couteau (2003).

15. Este yo sumergido en su entorno aparece en los textos Journal du dehors (1993) y Regarde les lumières mon amour (2014), con forma de diario, en el que Annie Ernaux comenta, en el primero, sus deambulaciones por París y las afueras, y relata en el segundo sus salidas durante un año al centro comercial parisino Les Trois-Fontaines, cercano a su casa. 
vérité sensible. J'ai toujours écrit de moi et hors de moi. (Ernaux, 2011c: 7).

Esta práctica sutil alcanza quizás su mayor consecución en Mémoire de fille, obra en la que la mujer escritora, je, se distancia de la joven que fue, refiriéndose a ella como elle. "C'est l'absence de sens de ce que l'on vit au moment où on le vit qui multiplie les possibilités d'écriture" (Ernaux, 2016: 151). No le es fácil escribir sobre sus recuerdos personales porque "il n'y a pas de vraie mémoire de soi" (Ernaux, 1999: 39). Por ello, para aprehender la verdad de lo que vivió en el pasado, recurre a menudo a los recuerdos de los demás, que son los archivos colectivos de un determinado grupo social, que validan o desmienten detalles de los recuerdos personales y ayudan a aclarar "cette opacité du présent" (Ernaux, 2016: 115) en el momento en que se vive. Este procedimiento queda evidenciado en L'autre fille, un relato en forma de carta que Annie Ernaux escribe a su hermana Ginette, a la que no conoció pues Ginette nació en 1932 y murió en 1938, dos años antes de que Annie Ernaux naciera. Ginette es una figura enigmática y desasosegante. Sus padres nunca hablaban a la joven Annie de la hermana muerta. No tiene ningún recuerdo directo de Ginette, salvo alguna fotografía. Annie Ernaux descubre tardíamente, con estupor y horror, que en una de esas fotografías donde aparecía un bebé -en el que ella había creído siempre reconocerse-, no era ella la fotografiada sino su hermana: "Quand j'étais petite, je croyais - on avait dû me le dire- que c'était moi. Ce n'est pas moi, c'est toi" (Ernaux, 2011a: 10). El propósito de Ernaux consiste en entablar una relación póstuma con ese ser desaparecido antes de tiempo, del que no tiene ningún recuerdo fiable, recogiendo aquí y allá como piezas de un puzle, los testimonios de allegados y algunas fotografías.

Cuando hace unas décadas parte de la crítica literaria ligada a los medios de comunicación, que divulgaba la literatura como cualquier otro bien de consumo fabricado por la industria del ocio, trató de definir las nuevas publicaciones autobiográficas que estaban proliferando, hizo circular el término autofiction ${ }^{16}$ acuñado años atrás por Serge Doubrovsky, quien proclamaba que la autobiografía había nacido en el siglo XVIII, siglo del individualismo, y que la autoficción era una mutación de la autobiografía

16. El término autofiction fue incorporado en el Petit Robert en la edición de 2001. 
que se producía concretamente en el siglo $\mathrm{XX}^{17}$. El término, hoy en día ya algo desgastado y a veces envuelto en matices despreciativos, pretendía instituir un nuevo género que multitud de críticos y escritores (Alain Robbe-Grillet, Gilles Mora y Claude Nori, Vincent Colonna, Philippe Vilain, Sophie Calle, Philippe Lejeune...) intentaron definir mediante neologismos variados. Era frecuente leer que ciertas obras de Annie Ernaux eran consideradas autoficciones, y ver aparecer su nombre junto al de escritores contemporáneos cuyas obras eran calificadas igualmente, tales como Georges Perec, Patrick Modiano, Michel Houellebecq, Christine Angot, o Catherine Millet y Virginie Despentes. La autoficción sugería esencialmente la idea de una síntesis entre autobiografía y ficción, y suponía, por lo tanto, una alteración del modelo paradigmático dominante de la autobiografía que alude por defecto a hechos verosímiles. Doubrovsky pensaba que la autobiografía contemporánea era una puesta en escena, un amaño de retazos de vida íntima aderezados adecuadamente; una autobiografía con carácter folletinesco que entraba dentro de la categoría de la ficción por tener como finalidad producir el máximo impacto en el lector.

Annie Ernaux, como sucede con Patrick Modiano, Premio Nobel de Literatura, habita ya, como se ha dicho, en el panteón de los clásicos. Muchos de sus libros se prescriben en los centros de enseñanza, algunos de ellos han sido adaptados al teatro ${ }^{18}$ y existe un premio literario Annie Ernaux ${ }^{19}$. Didier Alexandre, profesor de literatura francesa de los siglos XX-XXI en la Universidad París IV-Sorbona, incluye con frecuencia a Annie Ernaux en su programa de conferencias ${ }^{20}$ y dirige actualmente una tesis doctoral titulada "Écriture du moi à l'épreuve de la photographie: Annie Ernaux et Hervé Guibert". Ernaux es una autora de referencia obligada en el seno de la crítica universitaria internacional. La figura que compacta autor, personaje y narrador, así como los temas clave de la obra, permiten acercamientos pluridisciplinares. Para los sociólogos, Ernaux es

17. Véase el artículo firmado por Doubrovsky, "Pourquoi l'autofiction?" (2003).

18. Jeanne Champagne ha adaptado varios textos de Annie Ernaux para su compañía "Théâtre écoute": Passion simple se representa desde 1994 -cf. el artículo de Roger Maria, "Passion simple?" (1994)-; L'Événement (articula varios textos extraídos de Ce qu'ils disent ou rien, Les armoires vides, La femme gelée y L'Événement); La femme gelée; Regarde les lumières mon amour; así como Les Années.

19. Premio creado por la ciudad de Saint-Leu-la-Forêt (le Val d'Oise), cercana a Lillebonne, ciudad natal de Annie Ernaux.

20. Didier Alexandre impartió una conferencia en abril de 2016 en la Maison de la Recherche de París-Sorbona, titulada "Le sexe et la mémoire chez Annie Ernaux". 
una de sus autoras predilectas.

\section{LA INFLUENCIA DE PIERRE BOURDIEU Y SIMONE DE BEAUVOIR}

En 1972, dos años antes de la publicación de Les Armoires vides (1974), Ernaux había leído con mucho interés dos libros fundamentales en la historia de la sociología que iban a orientarla hacia lo que ella misma denomina "auto-socio-biographie" (Ernaux, 2003: 21), un tipo de autobiografía en la que "toute fictionnalisation des événements est écartée" (Ernaux, 2003: 21): Les Héritiers: les étudiants et la culture (1964) y La Reproduction: éléments pour une théorie du système d'enseignement (1970) de Pierre Bourdieu y Jean-Claude Passeron. Ernaux afirmaría que estas lecturas fueron los detonantes -el "déclencheur" (Charpentier, 2005a: 160)- que la ayudarían a esclarecer, según comenta Isabelle Charpentier en un artículo sobre la obra de Ernaux, la "position qu'elle occupe dans le monde social, plus précisément [...] l'ensemble des positions qu'elle y a successivement occupé, pour devenir 'l'ethnologue de soi-même' (Ernaux, 1997:40)"(Charpentier, 2005b: 114). Ernaux confesaría a Charpentier: "J'ai gardé longtemps les petites feuilles de notes que j'avais prises sur ces deux ouvrages, trois fois rien en fait par rapport à l'impact assez extraordinaire et bouleversant que ces livres ont eu pour moi" (Charpentier, 2005a: 161).

El pensamiento de Pierre Bourdieu dotó a la joven Annie Duchesne de los instrumentos necesarios para abordar sin ambages el análisis de su propio mundo. El reconocimiento de Ernaux hacia el sociólogo ha perdurado: en 2013, se une a otros escritores para rendir homenaje a Bourdieu en un libro conmemorativo en el que se estima el valor de su herencia ideológica y de la actitud vital que le caracterizó, la insumisión. El artículo escrito por Ernaux pone de manifiesto la fuerte influencia que ejerció sobre ella un texto de Bourdieu en particular, La distinction. Critique sociale du jugement (1979), que le permitió reflexionar en los años 80 acerca de las costumbres y particularidades de las clases sociales, las diferencias entre su propia clase social (sus padres, su familia, los habitantes del barrio) y la de personas de su entorno (amigas del colegio o amigos de la universidad, el propio Philippe Ernaux, su futuro marido, los médicos, los profesores...). Pero también, a nivel personal, la ayudó a asumir y comprender, retrotrayéndose a su infancia y adolescencia, 
el origen del sentimiento de vergüenza que empezó a atormentarla y acomplejarla cuando alcanzó a distinguir los signos de las diferencias:

Si La distinction est philosophie, elle est aussi tableau d'histoire pour son analyse des modes de vie, et offre un vaste tableau de l'existence quotidienne des clases sociales des années 1960 et 1970. [...] Tout ce qu'on a vécu solitairement, la gêne, la honte de ne pas savoir comment parler, comment se comporter, tout ce qu'on s'impute à soimême comme un manque de caractère ou de personnalité, cesse d'être un stigmate individuel (Ernaux, 2013a: 46, 48).

Por esta razón, Ernaux juzga necesario exteriorizarlo, escribirlo, porque "se taire, c'est taire sa réalité de femme et se ranger sous la domination masculine du monde" (Payot, 2000).

En varias ocasiones ha reconocido Annie Ernaux que la obra cumbre de Simone de Beauvoir, Le deuxième sexe, que leyó por primera vez durante el invierno de 1959-1960, le permitió reflexionar acerca de su propia condición de mujer porque desde muy joven había sufrido personalmente, y sin poder explicarlo, las diferencias que implicaba el hecho de ser del sexo femenino, de verse relegada, por convencionalismos morales y sociales, a la clase dominada. Pero a pesar de que Le deuxième sexe de Beauvoir le había legado "les clés pour comprendre la honte" (Ernaux, 2016: 110), no le dio "le pouvoir de l'effacer" (Ernaux, 2016: 110). Porque, según Gaston Bachelard:

Tous les espaces de nos solitudes passées, les espaces où nous avons souffert de la solitude, joui de la solitude, désiré la solitude, compromis la solitude, sont en nous ineffaçables. Et très précisément, l'être ne veut pas les effacer. Il sait d'instinct que ces espaces de sa solitude sont constitutifs (Bachelard, 1961 [1957]: 37).

Y añade Bachelard que esta imposibilidad de borrar lo más hiriente que persiste en el ser desde la infancia, se debe a que "au delà des souvenus, la maison natale est physiquement inscrite en nous. Elle est un groupe d'habitudes organiques" (Bachelard, 1961 [1957]: 42). Lo mismo ocurre 
con las costumbres psíquicas, que quedan también albergadas dentro de esa casa natal que representa mucho más que un espacio físico.

Aunque de procedencia social y de educación distintas, Simone de Beauvoir y Annie Ernaux -si bien Annie Ernaux es una intelectual de izquierdas como lo fue Beauvoir-comparten el mismo interés por poner de manifiesto el mundo parco y sofocante de la mujer contemporánea, relegada a un papel subsidiario dentro de la sociedad y en el seno de la familia. El primer libro de Ernaux en el que se aprecia la influencia de Beauvoir es sin duda La femme gelée. En sus primeras páginas, Ernaux pinta el retrato de las mujeres de su propia familia, rudas, pragmáticas, entrenadas para el trabajo y servir a los demás, sacrificadas, despreocupadas de sí mismas:

Mes femmes à moi, elles avaient toutes le verbe haut, des corps mal surveillés, trop lourds ou trop plats, des doigts râpeux, des figures pas fardées du tout ou alors le paquet, $d u$ voyant, en grosses taches aux joues et aux lèvres. [...] elles avaient travaillé ou travaillaient aux champs, ̀̀ l'usine, dans des petits commerces ouverts du matin au soir (Ernaux, 1981: 9).

Una obra más tardía, L'Occupation (2002), podría leerse como una versión actualizada de la obra de Beauvoir La femme rompue (1967) -cuyo título, por otra parte, podría hacer sospechar que sirvió de inspiración al de La femme gelée de Ernaux-, libro con el que guarda también un cierto parecido, ya que ambos hacen referencia a una vida matrimonial llena de sinsabores. L'Occupation y La femme rompue, a la vez que exponen y analizan un sentimiento poco honroso, considerado socialmente abyecto, los celos, y su padecimiento por parte de la mujer, denuncian la libertad del hombre, socialmente reconocida e incluso valorada, para contravenir los acuerdos tácitos de la relación de pareja, entablando relaciones paralelas con otra mujer. La historia contada es parecida también: una mujer (la narradora) vive en un estado de indefensión, agarrotada por la educación, el engaño de su compañero sentimental, y tiende a victimizarse. En $L a$ femme rompue, la narradora, sabedora de que Maurice, su marido, se encuentra con su amante Noëllie, sufre imaginando lo que hacen:

Ils sont en pyjama, ils boivent du café, ils sourient... Cette 
vision-là me fait mal. Quand on se cogne à une pierre, on sent d'abord le choc, la souffrance vient après: avec une semaine de retard, je commence à souffrir. Je ratiocinais, j'écartais cette douleur qui fond sur moi ce matin: les images. [...] J'ai ouvert son placard. J'ai regardé ses pyjamas, ses chemises, ses slips, ses maillots de corps; et je me suis mise à pleurer. Qu'une autre puisse caresser sa joue à la douceur de cette soie, à la tendresse de ce pullover, je ne le supporte pas (Beauvoir, 1967: 140-141).

En L'Occupation, Ernaux se imagina también a su amante Philippe W. (en la realidad, Philippe Vilain) -pero con menos recato que Beauvoir ${ }^{21}$ "dans le lit d'une autre femme [qui] peut-être fait [...] le même geste, de tendre la main et de saisir le sexe. [...] Pendant des mois, j'ai vu cette main et j'avais l'impression que c'était la mienne" (Ernaux, 2002: 12).

Al igual que Simone de Beauvoir, Annie Ernaux -como también Hélène Cixous- ha apoyado y sigue apoyando las causas de las mujeres y el activismo feminista. En una entrevista que la escritora concedió al diario canadiense La Presse con motivo de la publicación de Mémoire de fille, la periodista pregunta a Annie Ernaux si se trata de un libro feminista. La respuesta de Annie Ernaux es contundente: "Je vais vous dire une chose: je me demande comment on peut ne pas être féministe. De la même façon, je ne comprends pas qu'on puisse avoir une vision des classes et de la domination qui soit de droite et conservatrice. Pour moi, c'est la même chose" (Collard, 2016).

En otras ocasiones, Annie Ernaux ha reconocido sentirse también cercana a Jean Genet porque, al igual que él, procede de un mundo proletario y accedió al "savoir intellectuel par effraction" (Ernaux \& Jeannet, 2003: 34). Logró internarse en la clase superior, asimilar la lengua culta, para hacer de ella un instrumento de afirmación de sí misma, no sin cierto recelo y sentimiento de culpabilidad. En un texto breve incluido en Retour à Yvetot (2013) en el que alude a Jean Genet, retoma algunas de las reflexiones llenas de dudas que le son propias, acerca de cuál habría sido la modalidad de escritura más correcta en su caso, siendo una "immigrée

21. Beauvoir permanece muy pudorosa cuando alude al sexo como relación física, a pesar de que el título de su libro Le deuxième sexe levantara cierto revuelo cuando se publicó, poco antes de que el mayo 68 convulsionara Francia. 
de l'intérieur":

[...] Comment écrire, de quelle façon écrire? Est-ce que moi, la petite fille de l'épicerie de la rue du Clos-des-Parts, immergée enfant et adolescente dans une langue parlée populaire, un monde populaire, je vais écrire, prendre mes modèles, dans la langue littéraire acquise, apprise, la langue quej'enseigne puisque je suis devenue professeur de lettres? Est-ce que, sans me poser de questions, je vais écrire dans la langue littéraire où je suis entrée par effraction, "la langue de l'ennemi" comme disait Jean Genet, entendez l'ennemi de ma classe sociale? Comment puis-je écrire, moi, en quelque sorte immigrée de l'intérieur? (Ernaux, 2013b: 31).

A las figuras influyentes de Bourdieu, Beauvoir y Genet, habría que añadir finalmente la de Jean-Paul Sartre. A los dieciséis años, Annie Ernaux no sabe nada de Sartre, salvo que es un filósofo nihilista. La lectura de La Nausée, considerado un libro incendiario, va a cambiar radicalmente su visión del mundo. El título del artículo que Ernaux escribe en 2005 recordando la primera lectura que hizo de La Nausée, es de por sí explícito: "Le diable est venu à mon lit" -el diablo es Sartre que ha tentado a la joven Annie mientras leía La Nausée tumbada en la cama de su habitación en la casa familiar de Yvetot:

"Quelque chose m'est arrivé", ce sont les premiers mots du journal de Roquentin, au début de La Nausée. À 16 ans, à moi aussi il m'est arrivé quelque chose au cours de la lecture, comme un miroir. L'adolescente vivant dans un imaginaire alimenté par les romans sentimentaux est saisie par le collet et ramenée dans la matérialité des gestes et des objets, la sensation épaisse du présent, immergée dans ce qui jusque-là n'était qu'un mot vague: l'existence (Ernaux, 2005a). 


\section{LA VERGÜENZA DE SER UNA "TRÁNSFUGA SOCIAL" REVERTIDA EN FUERZA IMPULSORA DE LA ESCRITURA AUTOBIOGRÁFICA}

El tema de la vergüenza como desestimación de su propia persona y condición, no sólo está presente en el libro de Ernaux La Honte (1997a); recorre toda su obra impregnándola de una atmósfera de inefable melancolía. La vergüenza ha creado una herida narcisista persistente, tiene un poder indestructible: "La grande mémoire de la honte, plus minutieuse, plus intraitable que n'importe quelle autre. Cette mémoire qui est en somme le don spécial de la honte" (Ernaux, 2016: 18-19). La vergüenza en Ernaux aparece sobre todo en relación con el tema de la sexualidad y de la imagen de sí misma, la imagen social, la que le devuelven los demás. De ahí que puedan distinguirse dos tipos de vergüenza, como lo señala la propia Ernaux: la vergüenza social, que vertebra la obra desde Les armoires vides, y la vergüenza sexual, de la que es objeto la joven Annie Duchesne en el campamento de verano durante aquel "été de jeunesse" (Ernaux, 2016: 77), y que aparece circunscrita al verano de 1958 en Mémoire de fille, aunque también subyace en Ce qu'ils disent ou rien y L'Événement donde se narra el aborto. En Mémoire de fille cuenta Ernaux cómo, por primera vez en su vida, la joven Annie, elle, tiene relaciones físicas no sólo con el monitor jefe del campamento, el más guapo y por el que se deja seducir, sino también con otros monitores: "elle était passée de bras en bras entre les deux nuits passées avec lui [H.]" (Ernaux, 2016: 97). A la mañana siguiente de haber estado con H., le gastan la broma del balde de agua sobre la puerta. Otro día, en el espejo de su habitación le han dejado un mensaje escrito con su dentífrico de color rojo -"Vive les putains" (Ernaux, 2016: 63)-y se siente "humiliée par les autres" (Ernaux, 2016: 78). En un pasaje de Mémoire de fille, Ernaux da a entender que la vergüenza sexual, propia de la juventud, la superó a la edad adulta, dando a entender con ello que la vergüenza social es mucho más tenaz:

[La honte sexuelle]. C'est une autre honte que celle d'être fille d'épiciers-cafetiers. C'est la honte de la fierté d'avoir été un objet de désir. D'avoir considéré comme une conquête de la liberté sa vie à la colonie. Honte de Annie qu'est-ce que ton corps dit, de On n'a pas gardé les cochons ensemble, 
de la scène du tableau d'affichage. Honte des rires et du mépris des autres. C'est une honte de fille (Ernaux, 2016: 99).

La vergüenza como sentimiento alienante tiene una contrapartida: es la mayor fuente de inspiración para la escritora. Así lo resume Ernaux: “'[...]j'avais grandi sans honte sociale, sans honte sexuelle. L'une et l'autre me sont tombées dessus. La deuxième, l'été 58. La double aliénation où je puise tout ce que j'écris, mais à l'aveugle" (Ernaux, 2011c: 44).

La Honte es una suerte de repertorio de los elementos que distinguen las clases sociales y de los fundamentos de las relaciones de clase. Aquí, Ernaux lleva a cabo un trabajo preciso de objetivación de los modos de vida de una comunidad concreta en un tiempo y espacio determinados, la de su infancia, describiendo los barrios y la organización de la ciudad, la disposición material de los objetos en la vivienda, los comportamientos, los cuidados de higiene, consignando fórmulas de cortesía, así como recordando los valores morales dominantes y las normas a respetar. En opinión de Christian Baudelot (2004), La Honte es una suerte de manual de etnografía destinado al uso de neófitos y, si fuera ilustrado con fotografías, sería un buen libro de etnografía.

La vergüenza en Annie Ernaux es analizada retrospectivamente, como se ha visto, a raíz de la lectura de Bourdieu principalmente. Gracias a ella, le fue posible dar un nombre al malestar que empañaban sus recuerdos. Ernaux constata que la vergüenza nace de la mirada que los demás, los del otro mundo, de la clase social superior, proyectan sobre ella, pero también proviene de la comparación que establece Ernaux como sujeto avergonzado entre su mundo, su intimidad, su cuerpo, que los otros desestiman, y el mundo -con sus propiedades físicas e intelectuales- de los otros. Al mismo tiempo esa mirada ajena le señala cuál es el lugar que le corresponde a ella concretamente en el ámbito social. La vergüenza es una reacción de humillación ante el juicio de los otros; genera en Ernaux, como sujeto avergonzado, a la vez en el pasado y en el presente, un juicio despreciativo sobre sí misma; desencadena una relación de inferioridad / superioridad entre ella misma y los demás; le señala la superioridad distintiva de los demás. La vergüenza engendra una falta de estima personal que Ernaux decide combatir con la escritura, sirviéndose de la lengua culta que pertenece a los que le han hecho avergonzarse. Escribe 
desde la fractura social, la que separa los dos mundos de los que, a la edad adulta, participa a la vez, el mundo de los dominados (las clases humildes, sus orígenes) y el de los dominantes (intelectuales, clases pudientes), lo que imprime a su escritura una doble tendencia, un double bind ${ }^{22}$, hacia lo popular y hacia lo intelectual, y que se hace sentir, entre otras cosas, en la intercalación de elementos del léxico popular de sus orígenes en esos textos que publicará Gallimard, como sucede en La Place:

Le déchiffrement de ces détails s'impose à moi maintenant, avec d'autant plus de nécessité que je les ai refoulés, sûre de leur insignifiance. Seule une mémoire humiliée avait pu me les faire conserver. Je me suis pliée au désir du monde où je vis, qui s'efforce de vous faire oublier les souvenirs $d u$ monde d'en bas comme si c'était quelque chose de mauvais goût (Ernaux, 1983: 65).

A partir de la edad de doce años, la joven Annie, al entrar en contacto con el mundo privilegiado del colegio privado religioso de Yvetot, empieza a descubrir las diferencias y las desigualdades evidentes entre ella y sus compañeras. Ellas tienen otro sentido de lo que está bien y de lo que está mal, tienen un sentido estético que las hacen predominantes y les confiere poder, el poder en particular de avergonzar a las que no lo tienen, como la joven Annie:

Entre douze et quatorze ans, je vais découvrir avec stupéfaction que c'est laid et sale, cette poussière, que je ne voyais même pas. Ce serpent de Brigitte, désignant un endroit dans le bas du mur: "Dis donc, il y a longtemps que ça n'a pas été fait!' Je cherche: "Quoi, ça?" Elle m'a montré le minuscule rebord de la plinthe, tout gris, en effet, mais comment, il fallait nettoyer là aussi, j'avais toujours cru que c'était de la saleté normale, comme les traces de

22. La hipótesis del double bind (trad.: "doble vínculo" o "doble dependencia") es desarrollada a partir de 1956 por Gregory Bateson, Don D. Jackson, Jay Haley y John Weakland en un intento de definición de la esquizofrenia. Véase a este respecto Double Bind: the Foundations of the Communicational Approach to the Family (Sluzki \& Ransom, 1976 [1960]), y en particular el artículo "Toward a Theory of Schizophrenia" (Bateson et alii, 1976). 
doigts aux portes et le jaune au-dessus de la cuisinière. Vaguement humiliée de constater que ma mère manquait à l'un de ses devoirs, puisque apparemment c'en était un [comme le signalaient] Femme pratique [et] Bonnes soirées (Ernaux, 1981: 22).

\section{CONCLUSIÓN}

Cuando se dio a conocer la obra autobiográfica de Annie Ernaux, se pensó en un principio que suponía una continuación de las reivindicaciones defendidas por los movimientos feministas de los años 60-70 y del pronunciamiento compartido por Marie Cardinal, Hélène Cixous o Andrée Chedid que consistía en la afirmación de su propia identidad, desembarazándose de las prerrogativas que la familia, las instituciones y la sociedad tenían sobre ellas. Al publicar La Place, Annie Ernaux dejó claro que se distanciaba de esta tendencia imprimiendo a su texto un carácter etnofamiliar y autorreferencial. El conjunto de su obra es un ejemplo de una nueva forma de entender la literatura, como fusión entre sociología, historia y literatura; sociología porque ha descrito los hábitos y la organización de su grupo social de origen y se ha representado a sí misma dentro de él; historia porque ha recopilado acontecimientos de un pasado común a varias generaciones; literatura porque ha sabido explotar los recursos estéticos de la lengua culta para relatar su propia vida teniendo en cuenta lo anterior. A lo que se añade el sello característico del sedimento de la vergüenza que se asume en el presente de la escritura. "La honte n'a jamais cessé de m'habiter"23, declararó Ernaux en el transcurso de una entrevista. Desde el punto de vista sociológico, Annie Ernaux es el reflejo de una sociedad en lucha contra sus propios arcaísmos, deseosa de reconciliarse con sus orígenes populistas y fascinada por los avances tecnológicos.

Quizás, como explica Patrick Modiano a propósito de su propia obra con ocasión de la publicación su último libro, Souvenirs dormants, todos los libros de Annie Ernaux no formen más que "un seul 'roman' écrit de manière discontinue" (Modiano, 2017: 17). "Le terme 'éternel retour' (1997).

23. Véase la entrevista a Annie Ernaux por B. Walter, "La honte n'a jamais cessé de m'habiter" 
pourrait servir de définition à une démarche littéraire. Se retourner sur certains épisodes que vous avez vécus, au présent, dans le désordre, et leur donner, avec le recul du temps, une certaine ligne musicale" (Modiano, 2017: 17).

\section{REFERENCIAS BIBLIOGRÁFICAS}

BACHELARD, G. (1961) [1957]. La poétique de l'espace. https:// gastonbachelard.org/wp-content/uploads/2015/07/BACHELARDGaston-La-poetique-de-l-espace.pdf [19/05/2017].

BATESON, G.M; JACKSON, D.; HALEY, J. \& WEAKLAND, J. (1976). "Toward a Theory of Schizophrenia". En Double Bind: the Foundations of the Communicational Approach to the Family, C. Sluzki \& R. Ransom (eds.), 3-22. Nueva York: Grune \& Stratton.

BAUDELOT, Chr. (2004). “'Briser des solitudes'... Les dimensions psychologiques, morales et corporelles des rapports de classe chez Pierre Bourdieu et Annie Ernaux". En Annie Ernaux: une cuvre de l'entre-deux, Fr. Thumerel (dir.), 105-114. Arras: Artois Presses Université.

BEAUVOIR, S. de (1949). Le deuxième sexe. París: Gallimard. (1967). La femme rompue. París: Gallimard.

BOURDIEU, Pierre (1979). La distinction. Critique sociale du jugement. París: Les Éditions de Minuit.

BOURDIEU, P. \& PASSERON, J.-C. (1964). Les Héritiers: les étudiants et la culture. París: Éditions de Minuit.

(1970). La Reproduction: éléments pour une théorie du système d'enseignement. París: Éditions de Minuit.

CHARPENTIER, I. (2005a). "La littérature est une arme de combat... Entretien avec Annie Ernaux". En Rencontres avec Pierre Bourdieu, G. Mauger (dir.), 159-175. Broissieux: Éditions du Croquant. (2005b). "'Produire une 'littérature d'effraction' pour 'faire exploser le refoulé social' - Projet littéraire, effraction sociale et engagement politique dans l'œuvre autosociobiographique d'Annie Ernaux". En L'Empreinte du social dans le roman depuis 1980, M. Collomb (dir.), 111-131. Montpellier: Centre d'Études du $\mathrm{XX}^{\mathrm{e}}$ siècle, Université 
Paul Valéry-Montpellier.

COLLARD, N. (2016). “Annie Ernaux: ce n'est pas simple d'être une femme" (entrevista). La Presse.Ca, http://www.lapresse.ca/arts/ livres/201605/17/01-4982487-annie-ernaux-ce-nest-pas-simpledetre-une-femme.php [10/06/2017].

DOMECQ, J.-Ph. (2002). Qui a peur de la littérature? París: Mille et une nuits.

(2007). "La passion pour l'écriture engendre la célébration janséniste de l'écritûûure". En "La littérature s'est-elle détournée du monde", Le Magazine littéraire 461 (febrero), 22-23.

DOUBROVSKY, S. (2003). "Pourquoi l'autofiction?". Le Monde (29 de abril).

ERNAUX, A. (1974). Les armoires vides. París: Gallimard.

(1977). Ce qu'ils disent ou rien. París: Gallimard.

(1981). La femme gelée. París: Gallimard.

(1983). La Place. París: Gallimard.

(1991). Passion simple. París: Gallimard.

(1993). Journal du dehors. París: Gallimard.

(1997a). La honte. París: Gallimard.

(1997b). "Je ne suis pas sortie de ma nuit". París: Gallimard.

(2000). L'événement. París: Gallimard.

(2001a). "Le saut dans le vide". En Merci Bernard Pivot, St. Benhamou (ed.), 22. París: Le Journal du Dimanche (Supplément gratuit au Journal du Dimanche du 18 mars 2001).

(2001b). Se perdre. París: Gallimard.

(2002). L'Occupation. París: Gallimard.

(2005a). "Le diable est venu à mon lit". Libération, http://www. liberation.fr/cahier-special/2005/03/11/le-diable-est-venu-a-monlit_512559[22/06/2017].

(2005b). L'usage de la photo. París: Gallimard.

(2008). Les années. París: Gallimard.

(2011a). L'autre fille. París: NiL Éditions.

(2011b). "Je voulais venger ma race" (entrevista con Grégoire Leménager). Le Nouvel Observateur, http://bibliobs.nouvelobs.com/ romans/20111209.OBS6413/annie-ernaux-je-voulais-venger-marace.html [02/06/2017).

(2011c). Écrire la vie. París: Gallimard. 
(2013a). "La distinction, œuvre totale et révolutionnaire". En Pierre Bourdieu. L'insoumission en héritage, E. Louis (dir.), 17-48. París: Presses Universitaires de France. (2013b). Retour à Yvetot. París: Mauconduit. (2014). Regarde les lumières mon amour. París: Seuil. (2016). Mémoire de fille. París: Gallimard.

ERNAUX, A. \& JEANNET, F.-Y. (2003). L'écriture comme un couteau. París: Stock.

HAKEM, T. (2017). “Kamel Daoud: 'Écrire est une résistance, une façon de ne pas mourir" (entrevista con Kamel Daoud). France Culture, https://www.franceculture.fr/emissions/le-temps-des-ecrivains/ emission-speciale-kamel-daoud [28/08/2017].

HOGGART, R. (1970). La Culture du pauvre. París: Éditions de Minuit. LAACHER, S. (1991). "Annie Ernaux ou l'inaccessible quiétude. Entretien avec Annie Ernaux. Suivi d'un entretien avec l'écrivain". Politix 14, vol. 4, 73-78.

MARIA, R. (1994). “Passion simple?”. L'Humanité (19 de febrero).

MODIANO, P. (2017). "Souvenirs dormants" (entrevista). Bulletin Gallimard 519, 17.

PAYOT, M. (2000). "Annie Ernaux: 'un moment violent"” (entrevista). L'Express - Livres, 13/04.

SCHUDSON, M. (1995). The Power of News. Cambridge: Harvard University Press.

SLUZKI, C. \& RANSOM, R. (eds.) (1976) [1960]. Double Bind: the Foundations of the Communicational Approach to the Family. Nueva York: Grune \& Stratton.

WALTER, B. (1997). "La honte n'a jamais cessé de m'habiter" (entrevista a Annie Ernaux). Marie Claire (marzo).

Recibido el 27 de junio de 2017.

Aceptado el 15 de septiembre de 2017. 